\title{
Acute Ischemic Stroke as Complication in COVID-19 with Acute Respiratory Distress Syndrome in Intensive Care Unit: A Review
}

\author{
Anak Agung Ayu Putri Laksmidewi, Prysta Aderlia Sitanggang \\ Department of Neurology, Medical Faculty of Udayana University, Sanglah Hospital, Bali, Indonesia
}

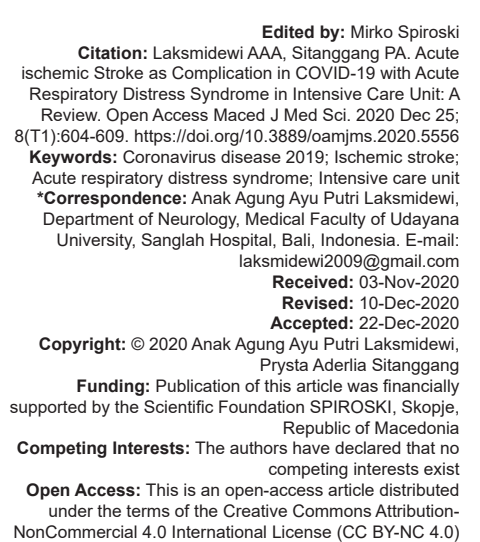

\section{Abstract}

Coronavirus disease 2019 (COVID-19) due to severe acute respiratory syndrome coronavirus 2 (SARS-CoV-2) infection has broad spectrum of manifestation ranging from asymptomatic cases to multi-organs failures. Cerebrovascular disease COVID-19 patients are still a big issue among neurologist. Neurologic manifestations are shown to be the first or late presentation in patients with SARS-CoV-2 infection. Ischemic stroke had happened majority than hemorrhage stroke in patients hospitalized with severe COVID-19 and comorbid such as hypertension, diabetes mellitus, or cardiovascular disease. Acute respiratory distress syndrome is predictable complication of COVID-19 that will ended with prolonged hospitalization and comprehensive management in intensive care unit (ICU). Anticoagulant is believed to have proven advantage to prevent this thrombogenesis. Patients with acute ischemic stroke as COVID-19 have poorer prognosis. Managing patients with ischemic stroke within the ICU are challenging due to prior use of anticoagulant as preventive of thrombosis that increase the risk of intracranial hemorrhage.

\section{Introduction}

The outbreak of coronavirus disease 2019 (COVID-19) is a devastating pandemic that being a significant threat to international health with more than 27 million confirmed cases and more than 800 confirmed death until September 2020 [1]. This disease is caused by severe acute respiratory syndrome coronavirus 2 (SARSCoV-2), a beta-coronavirus that associated with SARS and Middle East respiratory syndrome [2]. SARS-CoV-2 is an enveloped, positive sense, single stranded RNA virus and discovered in human, bats, and other wild animals [2]. In late December 2019, the virus was related to clusters of patients with pneumonia linked to seafood and wholesale market in Wuhan, Hubei Province, China [2]. The clinical spectrum of the disease forms asymptomatic infection, mild symptoms (fever, dry cough, and fatigue) to severe complications that ended with mortality [3], [4], [5]. Multiple organ failures are severe complications of COVID-19 includes acute respiratory distress syndrome (ARDS), arrhythmia, and acute heart injury, which is need transferred to intensive care unit (ICU) [3], [4], [6].

COVID-19 patients whom hospitalized with respiratory manifestation with appearance of viral pneumonia at first admission, they may develop to
ARDS about 8 days from the first symptoms [6], [7]. Shortness of breath or dyspnea is the sign of lacking of oxygen, so the need of high-flow oxygen therapy or invasive ventilation in ICU are needed for ARDS patient with COVID-19 [6], [8]. The lung involvement shows in chest computed tomography (CT) scan showing ground-glass opacity with shadows of consolidation or cord like in multiple lung lobes [3], [4], [5]. Huang et al. [3] reported that consolidated bilateral multiple and subsegmental areas of the lungs are typical findings on the chest CT scan of ICU patients within first admission. Patients with refractory hypoxemia and ARDS needed high flow oxygen theraphy such as invasive ventilation or even extracorporeal membrane oxygenation [6].

Besides the respiratory symptoms, the neurological symptoms also happened in patients with COVID-19 [9]. The symptoms are headache, hyposmia, hypogeusia, dizziness, altered consciousness, seizure, encephalopathy, neuromuscular injury, or cerebrovascular disease [9]. Thrombosis in the lung, limbs, heart, and brain has been reported in patients with COVID-19 [10], [11], [12], [13]. Both microvascular and large vessel thrombosis occur in severe COVID19 with the manifestation of venous thromboembolism, cardiovascular infarction, and pulmonary embolism [14]. Ischemic stroke is a potential condition related by the 
COVID-19 [15], [16]. The identification of ischemic stroke is related with acute ARDS [17]. Patients hospitalized with severe COVID-19 in ICU show the sign of coagulopathy with serious consequences in mortality and morbidity [18]. Patients with stroke associated with COVID-19 have more severe outcomes and higher mortality than non-COVID-19 ischemic stroke [19]. We will discuss the mechanism COVID-19 with ischemic stroke in hospitalized patients with ARDS in ICU.

\section{COVID-19 Patients with ARDS in ICU}

The most common symptoms appeared in patients with COVID-19 are fever, fatigue, dry cough, myalgia, and dyspnea [3], [6], [20], [21]. Patients with older age have more comorbidities such as hypertension, diabetes, cardiovascular disease, and cerebrovascular disease so they are profound to develop severe manifestation and organ damage [6], [20], [22], [23]. Wang et al. [6] reported that $26 \%$ patients with COVID19 were admitted and transferred to the ICU due to organ dysfunction development including ARDS, arrhythmia, acute cardiac injury, and shock. ICUpatients with COVID-19 and ARDS received high-flow oxygen therapy, non-invasive ventilation, and invasive ventilation to support the high oxygen demand [6].

SARS-CoV-2 infects mostly in respiratory and damages directly or indirectly the lungs by abrupt systemic inflammatory response [24]. The main cause of COVID-19 cause ARDS is damage of the alveolar epithelial cells and endothelial cells of blood vessels in all organs [24]. Chen et al. [22] showed that $17 \%$ patients with COVID-19 and ARDS had symptoms of dyspnea and hypoxemia. The mismatch of oxygen ventilation-perfusion or shunts intrapulmonary results a hypoxic respiratory failure condition [24]. Modalities to diagnose COVID-19 ARDS must include the Berlin 2012 ARDS diagnostic criteria of acute hypoxemic respiratory failure; presentation of worsening respiratory symptoms within 1 week; bilateral airspace disease on chest X-ray, CT, or ultrasound that is not fully explained by effusions, lobar or lung collapse, or nodules; and cardiac failure is not the primary cause of acute hypoxemic respiratory failure [25], [26]. Parameters for determine the patients with clinical condition leads to ARDS are respiratory rate and $\mathrm{SpO}_{2}$ [25]. If the patients fits to any one of the following conditions, respiratory rate $\geq 30$ breaths $/ \mathrm{min} ; \mathrm{SpO}_{2} \leq 92 \%$; and $\mathrm{PaO}_{2} / \mathrm{FiO}_{2}$ $\leq 300 \mathrm{mmHg}$; they may have severe COVID-19 and require further evaluations [25]. These patients had worsening from the first common symptoms to dyspnea and ARDS in 8-12 days, then they need oxygen therapy afterward [6], [23], [24].

Abnormalities of laboratory results such as neutrophilia, Iymphocytopenia, elevated end-organ indices (aspartate serum transaminase, urea, lactate dehydrogenase) elevated inflammation indices (high sensitivity C-reactive protein and serum ferritin), and elevated coagulation function-related indicators (prothrombin time [PT] and D-dimer) may leads to higher risk of ARDS to develop [23]. Spiezia et al. [27] reported the increased of hypercoagulable state in COVID-19 patients with respiratory failure than consumptive coagulopathy (disseminated intravascular coagulation [DIC]). Infection increases the level of fibrinogen and fibrin polymerization, then promote fibrin formation and deposition of D-dimer [28]. DIC is found in patient with sepsis and organ dysfunction as a result of activated monocytes and endothelial cells to the point release of cytokines [28], [29].

\section{Severe COVID-19 Relations with Acute Ischemic Stroke}

The spread of COVID-19 worldwide with various clinical symptoms related to the systemic infection of the SARS-CoV-2 virus within the body may also impact the central nervous system besides the respiratory system. With the evidence of ischemic stroke in patients in New York, United states, during hospitalization with COVID-19, about $0.9 \%$ patients had ischemic stroke [30]. Qin et al. report the cohort study of COVID-19 patients with a history of stroke in China is $2.7 \%$ [31]. The median age patients with stroke and COVID-19 are 63 years with hypertension and cardiovascular diseases as concomitant [31]. Elderly people have more comorbidities so they are more likely to be infected and to develop more severe symptoms in COVID-19 [31]. Yaghi et al. [30] reported from the 32 patients with ischemic stroke with COVID-19, 56.2\% developed the ischemic stroke during hospitalization for COVID-19 respiratory symptoms. The patients with history of stroke and COVID-19 have higher risk of poor outcome due to increased risk for ARDS with the need of mechanical ventilation support and intensive care admission [31].

Hypercoagulable state in patients with COVID-19 shows abnormally laboratory findings of high D-dimer concentrations, prolonged PT, thrombocytopenia, and elevation fibrinogen level [32]. Those are final product of unregulated hyperinflammation immune response to SARSCoV-2 [3], [33]. The pro-inflammatory cytokines in serum such as interleukin (IL) $1 \beta$, IL12, interferon (IFN) $\mathrm{y}$, IFN- $\mathrm{y}$-induced protein 10, and monocyte chemoattractant protein- 1 that leads the activation of T-helper (Th) 1 cell response are increased [3]. The Th2 cytokines (IL4 and IL10) increase by the initiation of SARS-CoV-2 that suppresses inflammation [3]. As response to the infection, the excessive inflammation 
often ended in impairment to down regulate the activated macrophages and lymphocytes. This condition called hemophagocytic lymphohistiocytosis (HLH)-like syndrome [33]. COVID-19 may suppress the CD4+ $\mathrm{T}$ cell IFN-Y production by secondary HLH [33].

The role of platelets in viral clearance is by interacting with leucocytes to trigger recruitment and tissue infiltration [33]. The critically ill patients have thrombocytopenia and multi-organ failure related to this mechanism. The strong stimulation of neutrophils and other monocytes and eosinophils, release extracellular traps (ETs) in a process known NETosis [33]. Tissue neutrophil ETS (NETs) cause activation of platelet that induces platelet aggregation through toll-like receptors on platelets and other cells [33]. Platelet aggregation happened after the activation of platelet signaling through major adhesion receptor, integrin $\alpha \mathrm{llb} \beta 3$ [33]. Factor XII (FXII) is activated into XIla by the endogenous activator (nucleic acids RNA/DNA, NETs, polyphosphate, and heparin) then activates the intrinsic coagulation pathways [34]. Thrombin activation and fibrin generation is the last product after the activation of FXI into the FXIa in intrinsic pathway [34].

SARS-CoV-2 infects the host using the angiotensin converting enzyme-2 receptor as portal of entry, which these receptors are expressed in several organs such as lungs, heart, kidney, and intestine [35]. The receptor also expressed in endothelial surfaces that viral invasion of the vascular endothelium triggers initiation of thrombotic and inflammatory cascades leading into internal organ injury [34]. The viral inclusion in the endothelial cells is associate with accumulation of inflammatory cells, then results in apoptotic bodies in the related organ [35]. The induction of endotheliitis as a result of SARS-CoV-2 infection is triggering the thrombotic and inflammatory cascades that lead to internal organ injury [35]. This microcirculatory dysfunction is happened as result to endothelial dysfunction in more vasoconstriction state with ischemic organ, inflammation and tissue edema, and procoagulant state [35]. Von Willebrand Factor (VWF) is active after endothelial injury that impaired the vascular integrity and aggregates platelets [33]. Ultra-large VWF fibers are formed after inflammation process and became immobilized within endothelial cells that very adhesive under shear conditions [33]. The thrombosis may involve in all vascular beds including the microvascular circulation and large vessel after the inflammation and the coagulation process [33], [34]. White thrombus and red thrombus which has more platelets and red blood cells trapped in the fibrin strands as a result of high shear stress [36]. The relationship between hyperinflammation and hypercoagulation state in COVID-19 is shown in Figure 1.

\section{Treatment Approach of Acute Ischemic Stroke in ICU with COVID-19}

Recommendation from guidelines for early management of patients with acute ischemic stroke in 2019 [37], the early management for patients with mild stroke but disabling symptoms can be treated with recombinant-tissue plasminogen activator ( $r$-TPA), also known as alteplase, within $3 \mathrm{~h}$ of ischemic stroke symptom onset or patient last known well or at baseline state. The use other fibrinolytic agents other than alteplase or tenecteplase is not recommended because of no shown benefit [37]. Bleeding risk should be considered within the given r-TPA by checking any abnormal platelet component [37]. Clearance of r-TPA is in the liver, then hepatic dysfunction in will result in high concentration of r-TPA in the serum and increase the risk of intra-cerebral hemorrhage [38]. Increased prothrombin time (PT), international normalized ratio (INR), and thrombocytopenia are associated with this coagulopathy due to liver dysfunction [38]. The dilemma in this situation related to patients in ICU with COVID19 is the use of anticoagulant as massive thrombosis prevention [27]. The current guidelines to use r-TPA in patients with the history of warfarin use are may be considered on a case-by-case basis as long the INR $\leq 1.7$ and/or PT < 15 s [37]. The use of low-molecular weight heparin in previous $24 \mathrm{~h}$ as prophylactic or treatment doses is harmful for r-TPA procedure [37].

Ntaios et al. [19] wrote about the outcome patients in COVID-19 ischemic stroke has higher mortality than non-COVID-19 ischemic strokes. In his report "characteristics and outcomes in patients with COVID-19 and acute ischemic stroke," about $19.7 \%$ patients with alteplase administration had complication hemorrhagic transformation of the infarct and malignant brain edema [19]. Potential explanation in this complication is related to vasculopathy induced by viral infection [19]. Otherwise, prognosis after r-TPA administration in acute ischemic stroke in COVID-19 and ARDS in ICU has been reported by Co et al. [39] by the improvement of National Institutes of Health Stroke Scale (NIHSS). The use of antithrombotic after $24 \mathrm{~h}$ of r-TPA administration and fluid management is the key in successful treatment in this situation [39].

Mechanical thrombectomy can be a treatment choice with suspicion of large vessel occlusion from non-invasive vessel imaging evaluation such as CT angiography (CTA) or magnetic resonance angiography [37]. This procedure is suitable in patients with internal carotid artery or proximal middle cerebral artery (identified by CTA) occlusion, NIHSS score $\geq 6$, Alberta Stroke Program Early CT Score $\geq 6$, no extensive ischemic changes in head CT scan, and treatment can be initiated within $6 \mathrm{~h}$ of symptoms onset [37]. The challenges within COVID-19 pandemic are the patient cannot be transferred rapidly to angiographic suite form 


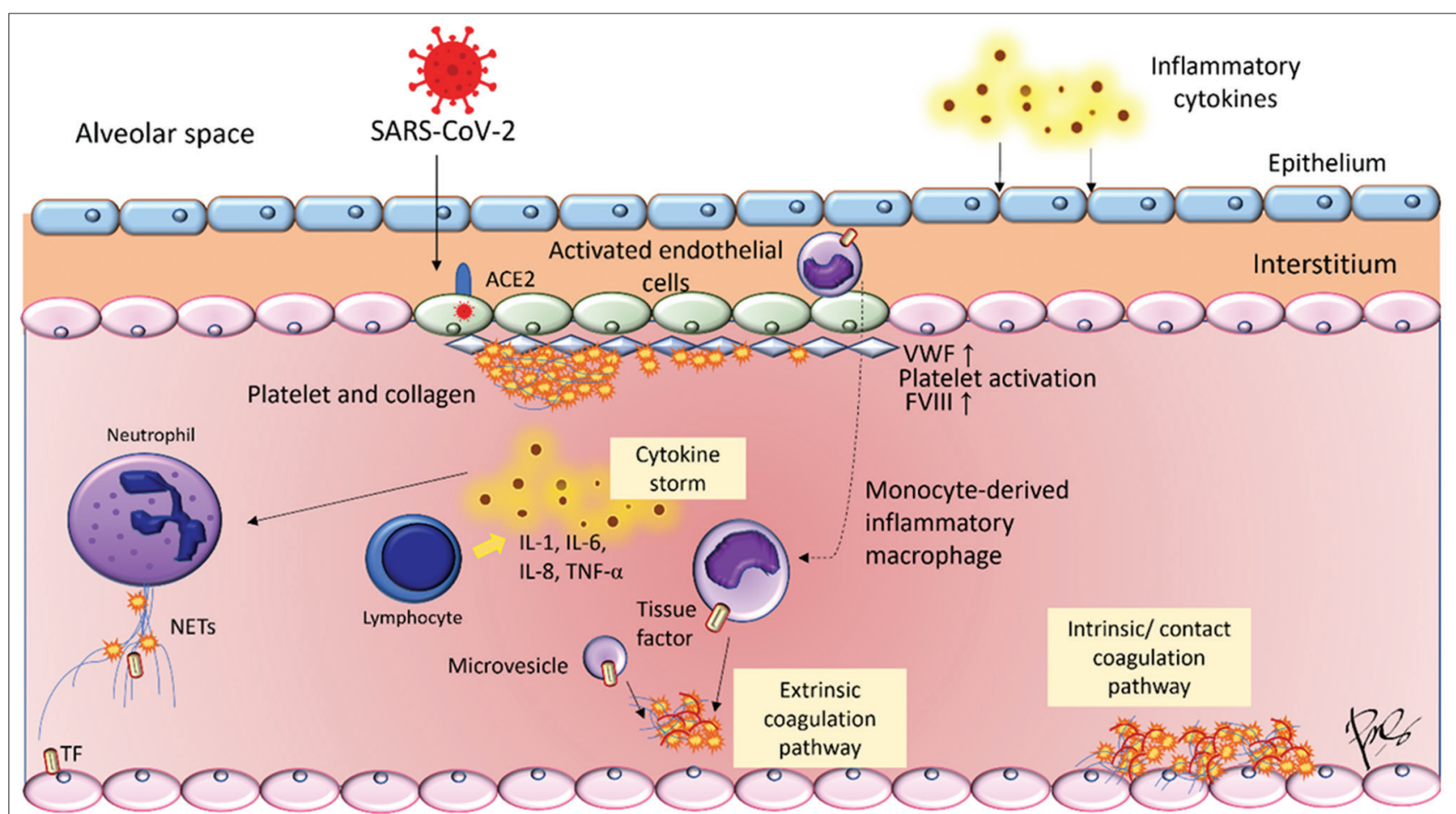

Legends:

Eymphocyte Endothelial cell

Figure 1: Pathophysiology of hyperinflammation and hypercoagulable state in coronavirus disease-2019

emergency department or from outside hospital due to added requirements [38].

Minor ischemic stroke or transient ischemic attack treatment should be immediate administration of aspirin or a combination of aspirin and clopidogrel [37]. The initial aspirin dose is $160-300 \mathrm{mg}$ with flexible administration through oral (swallow), nasogastric tube, or rectal [37]. The safety and usefulness of urgent anticoagulant are not well established and not recommended to preventing early recurrent stroke of patients with AIS [37]. The report in anticoagulant in acute ischemic stroke with COVID-19 is still limited. Dogra et al. reports hemorrhage stroke happened by the using of anticoagulant for prophylaxis or therapeutic dose in COVID-19 [40]. The use of anticoagulant therapy should be considered due to risk of intra cranial hemorrhage [40]. Future studies should compare the outcomes in patients with anticoagulant or antiplatelet in AIS with COVID-19.

Corticosteroid is commonly used in treating patients with severe COVID-19 due to their mechanism by inhibiting effect on inflammatory factors [41]. Fadel et al. [42] reported about the efficacy of using early corticosteroids to prevent progression of the disease and improve outcomes. ARDS patients that received corticosteroid had shortened ventilation times and increase the number of ventilator-free days. Specific use of dexamethasone in patients with COVID-19 may reduce the days of hospitalization than those in the usual care group [43]. Incidence of death in COVID-19 patients receiving invasive mechanical ventilation and receiving oxygen without invasive mechanical ventilation is lower in the usual care group in the Randomized Evaluation of COVID-19 Therapy (RECOVERY) trial [43]. Treatment for the patient COVID-19 with respiratory support that receives dexamethasone at a dose of $6 \mathrm{mg}$ once daily for up 10 days may reduce the 28-day mortality [43].

\section{Availability of Data and Material}

Data sharing is not applicable to this article as no datasets were generated or analyzed during the current study. 


\section{Authors' contributions}

All the authors contributed equally in this study and during preparation of this manuscript.

\section{References}

1. World Health Organization. Coronavirus (COVID-19) Data Geneva: World Health Organization; 2020. Available from: https://www.who.int/data\#reports. [Last accessed on 2020 Sep 10].

2. Zhu N, Zhang D, Wang W, Li X, Yang B, Song J, et al. A novel coronavirus from patients with pneumonia in China, 2019. N Engl J Med. 2020;382(8):727-33.

PMid:31978945

3. Huang C, Wang Y, Li X, Ren L, Zhao J, Hu Y, et al. Clinical features of patients infected with 2019 novel coronavirus in Wuhan, China. Lancet. 2020;395(10223):497-506. https://doi. org/10.1016/s0140-6736(20)30183-5

4. Guan WJ, Ni ZY, Hu Y, Liang WH, Ou CQ, He JX, et al. Clinical Characteristics of Coronavirus Disease 2019 in China. N Engl J Med. 2020;382(18):1708-20.

5. Liu K, Fang YY, Deng Y, Liu W, Wang MF, Ma JP, et al. Clinical characteristics of novel coronavirus cases in tertiary hospitals in Hubei Province. Chin Med J (Engl). 2020;133(9):1025-31. https://doi.org/10.1097/cm9.0000000000000744 PMid:32044814

6. Wang D, Hu B, Hu C, Zhu F, Liu X, Zhang J, et al. Clinical characteristics of 138 hospitalized patients with 2019 novel coronavirus-infected pneumonia in Wuhan, China. JAMA. 2020;323(11):1061-9. https://doi.org/10.1001/jama.2020.1585 PMid:32031570

7. Yang W, Cao Q, Qin L, Wang X, Cheng Z, Pan A, et al. Clinical characteristics and imaging manifestations of the 2019 novel coronavirus disease (COVID-19): A multi-center study in Wenzhou city, Zhejiang, China. J Infect. 2020;80(4):388-93. https://doi.org/10.1016/j.jinf.2020.02.016

PMid:32112884

8. Zheng Z, Peng F, Xu B, Zhao J, Liu H, Peng J, et al. Risk factors of critical and mortal COVID-19 cases: A systematic literature review and meta-analysis. J Infect. 2020;81(2):e16-25. https:// doi.org/10.1016/j.jinf.2020.04.021

PMid:32335169

9. Herman C, Mayer K, Sarwal A. Scoping review of prevalence of neurologic comorbidities in patients hospitalized for COVID19. Neurology. 2020;95(2):77-84. https://doi.org/10.1212/ wnl.0000000000009673

PMid:32345728

10. Cerasti D, Ormitti F, Pardatscher S, Malchiodi L, Picetti E, Menozzi R, et al. Multiple acute ischemic strokes in a COVID19 patient: A case report. SN Compr Clin Med. 2020;2020:1-5. https://doi.org/10.1007/s42399-020-00388-9

PMid:32838158

11. Avula A, Nalleballe K, Narula N, Sapozhnikov S, Dandu V, Toom S, et al. COVID-19 presenting as stroke. Brain Behav Immun. 2020;87:115-9. https://doi.org/10.1016/j. bbi.2020.04.077

PMid:32360439

12. Marone EM, Rinaldi LF. Upsurge of deep venous thrombosis in patients affected by COVID-19: Preliminary data and possible explanations. J Vasc Surg Venous Lymphat Disord. 2020;8(4):694-5. https://doi.org/10.1016/j.jvsv.2020.04.004 PMid:32305586

13. Guo T, Fan $Y$, Chen M, Wu X, Zhang L, He T, et al. Cardiovascular implications of fatal outcomes of patients with coronavirus disease 2019 (COVID-19). JAMA Cardiol. 2020;5(7):811-8. https://doi.org/10.1001/jamacardio.2020.1017 PMid:32219356

14. Tal S, Spectre G, Kornowski R, Perl L. Venous thromboembolism complicated with COVID-19: What do we know so far? Acta Haematol. 2020;143(5):417-24. https://doi. org/10.1159/000508233

PMid:32396903

15. Tsivgoulis G, Katsanos AH, Ornello R, Sacco S. Ischemic stroke epidemiology during the COVID-19 pandemic: Navigating uncharted waters with changing tides. Stroke. 2020;51(7):19246. https://doi.org/10.1161/strokeaha.120.030791

PMid:32496937

16. Katz JM, Libman RB, Wang JJ, Sanelli P, Filippi CG, Gribko M, et al. Cerebrovascular complications of COVID-19. Stroke. 2020;51(9):e227-31. PMid:32757751

17. Duroi I, Van Durme F, Bruyns T, Louage S, Heyse A. Fatal ischaemic stroke during COVID-19 and acute lung injury. Eur $J$ Case Rep Intern Med. 2020;7(6):001732.

PMid:32523931

18. Abou-Ismail MY, Diamond A, Kapoor S, Arafah Y, Nayak L. The hypercoagulable state in COVID-19: Incidence, pathophysiology, and management. Thromb Res. 2020;194:101-15. https://doi. org/10.1016/j.thromres.2020.11.012

PMid:32788101

19. Ntaios G, Michel P, Georgiopoulos G, Guo Y, Li W, Xiong J, et al. Characteristics and outcomes in patients with COVID19 and acute ischemic stroke: The global COVID-19 stroke registry. Stroke. 2020;51(9):e254-8. https://doi.org/10.1161/ strokeaha.120.031173

PMid:32787707

20. Rodriguez-Morales AJ, Cardona-Ospina JA, GutiérrezOcampo E, Villamizar-Peña R, Holguin-Rivera Y, EscaleraAntezana JP, et al. Clinical, laboratory and imaging features of COVID-19: A systematic review and meta-analysis. Travel Med Infect Dis. 2020;34:101623. https://doi.org/10.1016/j. tmaid.2020.101623

PMid:32179124

21. Dewi VT, Agung A, Putri AY, Sudiariani KA. Clinical manifestation and pathogenesis of nervous system involvement in severe acute respiratory syndrome coronavirus-2 infection. Asian J Pharm Clin Res. 2020;13(10):39006. https://doi.org/10.22159/ ajpcr.2020.v13i10.39006

22. Chen N, Zhou M, Dong $\mathrm{X}, \mathrm{Qu} \mathrm{J}$, Gong $\mathrm{F}$, Han $\mathrm{Y}$, et al. Epidemiological and clinical characteristics of 99 cases of 2019 novel coronavirus pneumonia in Wuhan, China: A descriptive study. Lancet. 2020;395(10223):507-13. https://doi.org/10.1016/ s0140-6736(20)30211-7

PMid:32007143

23. Wu C, Chen X, Cai Y, Xia J, Zhou X, Xu S, et al. Risk factors associated with acute respiratory distress syndrome and death in patients with coronavirus disease 2019 pneumonia in Wuhan, China. JAMA Intern Med. 2020;180(7):934-43. https://doi. org/10.1001/jamainternmed.2020.0994 PMid:32167524

24. Li X, Ma X. Acute respiratory failure in COVID-19: Is it "typical" ARDS? Crit Care. 2020;24(1):198. https://doi.org/10.1186/ s13054-020-02911-9 


\section{PMid:32375845}

25. Gibson PG, Qin L, Puah SH. COVID-19 acute respiratory distress syndrome (ARDS): Clinical features and differences from typical pre-COVID-19 ARDS. Med J Aust. 2020;213(2):54-6.e1. https:// doi.org/10.5694/mja2.50674

PMid:32572965

26. ARDS Definition Task Force, Ranieri VM, Rubenfeld GD, Thompson BT, Ferguson ND, Caldwell R, et al. Acute respiratory distress syndrome: The Berlin definition. JAMA. 2012;307(23):2526-33. https://doi.org/10.1001/2012. jama.11901 PMid:22797452

27. Spiezia L, Boscolo A, Poletto F, Cerruti L, Tiberio I, Campello E, et al. COVID-19-related severe hypercoagulability in patients admitted to intensive care unit for acute respiratory failure. Thromb Haemost. 2020;120(6):998-1000. https://doi. org/10.1055/s-0040-1710018 PMid:32316063

28. Tang N, Li D, Wang X, Sun Z. Abnormal coagulation parameters are associated with poor prognosis in patients with novel coronavirus pneumonia. J Thromb Haemost. 2020;18(4):844-7. https://doi.org/10.1111/jth.14768

PMid:32073213

29. Okamoto K, Tamura T, Sawatsubashi Y. Sepsis and disseminated intravascular coagulation. J Intensive Care. 2016;4(23):1-8. https://doi.org/10.1186/s40560-016-0149-0

30. Yaghi S, Ishida K, Torres J, Grory BM, Raz E, Humbert K, et al. SARS-CoV-2 and stroke in a New York healthcare system. Stroke. 2020;51(7):2002-11. https://doi.org/10.1161/ strokeaha.120.031606 PMid:32432996

31. Qin C, Zhou L, Hu Z, Yang S, Zhang S, Chen M, et al. Clinical characteristics and outcomes of COVID-19 patients with a history of stroke in Wuhan, China. Stroke. 2020;51(7):2219-23. https://doi.org/10.1161/strokeaha.120.030365 PMid:32466735

32. Iba T, Levy JH, Levi M, Thachil J. Coagulopathy in COVID-19. J Thromb Haemost. 2020;18(9):2103-9. https://doi.org/10.1111/ jth. 14975

\section{PMid:32558075}

33. Becker RC. COVID-19 update: Covid-19-associated coagulopathy. J Thromb Thrombolysis. 2020;50(1):54-67. https://doi.org/10.1007/s11239-020-02134-3

PMid:32415579

34. Spence JD, de Freitas GR, Pettigrew LC, Ay H, Liebeskind DS, Kase CS, et al. Mechanisms of stroke in COVID-19. Cerebrovasc Dis. 2020;49(4):451-8. https://doi.org/10.1159/000509581 PMid:32690850

35. Varga Z, Flammer AJ, Steiger $P$, Haberecker M, Andermatt R, Zinkernagel AS, et al. Endothelial cell infection and endotheliitis in COVID-19. Lancet. 2020;395(10234):1417-8. https://doi. org/10.1016/s0140-6736(20)30937-5

PMid:32325026

36. Poterucha TJ, Libby $\mathrm{P}$, Goldhaber SZ. More than an anticoagulant: Do heparins have direct anti-inflammatory effects? Thromb Haemost. 2017;117(3):437-44. https://doi. org/10.1160/th16-08-0620

PMid:27975101

37. Powers WJ, Rabinstein AA, Ackerson T, Adeoye OM, Bambakidis NC, Becker K, et al. Guidelines for the early management of patients with acute Ischemic stroke: 2019 Update to the 2018 guidelines for the early management of acute ischemic stroke: A guideline for healthcare professionals from the American Heart Association/American Stroke Association. Stroke. 2019;50(12):e344-418. https://doi.org/10.1161/ str.0000000000000215

\section{PMid:31662037}

38. Qureshi Al, Abd-Allah F, Al-Senani F, Aytac E, BorhaniHaghighi A, Ciccone A, et al. Management of acute ischemic stroke in patients with COVID-19 infection: Report of an international panel. Int J Stroke. 2020;15(5):540-54. https://doi. org/10.1177/1747493020923234

PMid:32362244

39. Co CO, Yu JR, Laxamana LC, David-Ona DI. Intravenous thrombolysis for stroke in a COVID-19 positive filipino patient, a case report. J Clin Neurosci. 2020;77:234-6. https://doi. org/10.1016/j.jocn.2020.05.006

\section{PMid:32414622}

40. Dogra S, Jain R, Cao M, Bilaloglu S, Zagzag D, Hochman S, et al. Hemorrhagic stroke and anticoagulation in COVID-19. J Stroke Cerebrovasc Dis. 2020;29(8):104984. https://doi. org/10.1016/j.jstrokecerebrovasdis.2020.104984

PMid:32689588

41. Wang Y, Ao G, Qi X, Zeng J. The influence of corticosteroid on patients with COVID-19 infection: A meta-analysis. Am J Emerg Med. 2020;S0735-6757(20)30528-3.

PMid:32616373

42. FadelR, MorrisonAR, VahiaA, SmithZR, ChaudhryZ, BhargavaP, et al. Early Short Course Corticosteroids in Hospitalized Patients with COVID-19. Clin Infect Dis. 2020;71(16):2114-20. https:// doi.org/10.1101/2020.05.04.20074609

PMid:32427279

43. RECOVERY Collaborative Group, Horby P, Lim WS, Emberson JR, Mafham M, Bell Jl, et al. Dexamethasone in hospitalized patients with Covid-19 preliminary report. N Engl J Med. 2020;2020:NEJMoa2021436. https://doi.org/10.1056/ nejmoa2021436

PMid:32678530 